\title{
Peningkatan Public Speaking bagi Siswa SMK Bina Nusa Slawi
}

\author{
Improving Public Speaking for Vocational School Students of Bina Nusa Slawi
}

\author{
Syaefani Arif Romadhon* $*^{1}$, Iin Indrayanti ${ }^{2}$, Mutiarawati ${ }^{3}$ \\ 1,2,3Politeknik Harapan Bersama, Indonesia \\ *Penulis Korespondensi \\ 1syaefani1984@gmail.com, ${ }^{2}$ iinindrayanti@poltektegal.ac.id, ${ }^{3}$ mutiarasutanto@gmail.com
}

Riwayat Artikel: Dikirim 28 Agustus 2021; Diterima 21 November 2021; Diterbitkan 30 November 2021

\begin{abstract}
Abstrak
Kegiatan berbicara atau yang dikenal dengan public speaking merupakan hal yang menakutkan bagi para siswa. Kendati mereka sering diminta untuk mempraktikkan presentasi di depan kelas, namun teknik penyampaian public speaking seringkali tidak diperhatikan. Ada beberapa teknik yang sebaiknya dikuasai dalam public speaking sehingga dalam penyampaiannya dapat tersampaikan dengan baik kepada audience. Pelaksanaan PKM kali ini bertujuan untuk memberikan pengetahuan terkait skill public speaking, meningkatkan keterampilan berbicara, melatih mental siswa untuk berbicara di hadapan orang banyak serta membekali siswa siswi dalam memasuki jenjang perkuliahan atau bekerja. Metode yang disampaikan pada kegiatan PKM ini yaitu ceramah dan praktik bersama 20 orang siswa dan siswi kelas XII SMK Bina Nusa Slawi. Siswa juga dibekali modul untuk mempermudah saat penyampaian dan siswa juga dapat mengulangi kembali materi tersebut saat di rumah. Siswa juga diberikan arahan terkait cara presentasi yang benar dalam bahasa Indonesia maupun bahasa Inggris yang sesuai dengan kaidah-kaidah public speaking. Selain teori dan praktik di kelas. Siswa juga diarahkan untuk mencermati beberapa tokoh-tokoh public speaking melalui kanal youtube. Secara garis besar kegiatan pengabdian kepada masyarakat di SMK Bina Nusa Slawi berjalan dengan baik. Antusiasme siswa luar biasa dilihat dari 80\% siswa yang merasakan pentingnya memiliki skill public speaking dan meningkatkan percaya diri. Siswa merasa terbantu dengan adanya kegiatan PKM ini karena memperoleh pengetahuan seputar public speaking dan teknik presentasi yang dapat digunakan untuk menunjang presentasi saat di kelas maupun sebagai bekal kelak di dunia kerja.
\end{abstract}

Kata kunci: Public Speaking, presentasi, komunikasi

\begin{abstract}
The activity of speaking or known as public speaking is a scary thing for students. Although they are often asked to practice presentations in front of the class, the technique of delivering public speaking is often not paid attention to. There are several techniques that should be mastered in public speaking so that the delivery can be conveyed well to the audience. This time, the implementation of PKM aims to provide knowledge about public speaking skills, improve speaking skills, mentally prepare students to speak in front of crowds, and equip students to enter lectures or work. The method presented in this activity is lecture and practice.with 20 students from SMK Bina Nusa Slawi. Students are also provided with modules to make it easier when delivering and students can also repeat the material at home. Students are also given directions regarding the correct way of presentation in Indonesian and English in accordance with the rules of public speaking. In addition to theory and practice in the classroom. Students are also directed to observe several public speaking figures through Youtube channel. In general, community service activity at SMK Bina Nusa Slawi are going well. Students' enthusiasm is extraordinary, as evidenced by the fact that 80 percent of students believe that having public speaking skills and increasing self-confidence are important. Students feel helped by this activity because they gain knowledge about public speaking and presentation techniques that can be used to support presentations in class or as a provision for later in the world of work.
\end{abstract}

Keywords: public Speaking, presentation, communication. 


\section{PENDAHULUAN}

Public Speaking bagi sebagian siswa merupakan hal yang baru, meskipun sering mereka lakukan dalam bentuk presentasi di depan kelas. Hal pokok dalam public speaking ini adalah menyampaikan ide atau gagasan secara lisan atau berbicara. Meskipun dari sejak dini kita seringkali berbicara namun fakta yang terjadi di lapangan adalah banyak individu yang kesulitan untuk menyampaikan ungkapan tersebut yang sesuai dengan kaidah public speaking. (Fitrananda et al., 2018) menyampaikan bahwa terdapat 2 faktor yang mempengaruhi kemampuan publik speaking seseorang, yaitu faktor internal dan eksternal. Terkait dengan faktor internal yaitu segala hal yang menempel pada diri individu, diantaranya faktor fisik (bibir, mulut, lidah, pita suara, gigi) dan faktor non fisik (tingkat kecerdasan, pola piker, minat, bakat, karakter, kepribadian). Berikutnya yaitu faktor eksternal sebagai contoh kebiasaan, level pendidikan, dan lingkungan pergaulan. Namun demikian, ketrampilan public speaking seseorang tidak hanya dijamin dengan 2 faktor tersebut, karena membutuhkan latihan secara terusmenerus agar potensi public speaking yang dimiliki dapat berkembang dengan optimal. Dalam menyampaikan presentasi atau praktik public speaking di depan kelas terkadang terdapat faktor penghambat yang cukup signifikan yaitu kecemasan. Seperti yang disampaikan oleh (Aryadillah, 2017), bahwa kecemasan adalah perasaan subjektif mengenai ketegangan mental yang menggelisahkan dan ketidakmampuan mengatasi suatu masalah atau tidak adanya rasa aman. Perasaan cemas tersebut dapat menimbulkan beberapa efek negatif diantaranya tegang, bingung, tidak dapat berkonsentrasi, tidak tenang, dan gagap dalam berkomunikasi, gemetar, berkeringat, detak jantung meningkat dan psikologis; panik.

Salah satu kajian tentang mengukur level kecemasan dalam public speaking dilakukan oleh (Raja, 2017). Dengan menggunakan angket yang melibatkan 50 orang siswa, ia menyatakan bahwa 75\%$90 \%$ siswa merasa takut, malu dan tidak nyaman berbicara dengan bahasa asing di depan orang lain. Ia pun menambahkan bahwa perasaan cemas adalah sebuah kewajaran dan normal terjadi pada setiap individu, khusus nya di kalangan pelajar. Namun, faktor kecemasan bukanlah faktor utama dalam berprestasi, melainkan kepercayaan diri. Seperti penelitian yang dilaksanakan oleh (Tridinanti, 2018). Hasil risetnya menyatakan bahwa terdapat hubungan yang sangat erat atau signifikan antara tingkat kepercayaan diri dengan prestasi seseorang. Bahwa seseorang dengan tingkat kepercayaan tinggi, maka akan memperoleh prestasi yang lebih baik. Selain itu, berlatih dalam kelompok merupakan salah satu pilihan dalam mengurangi perasaan cemas ataupun gelisah dan nervous pada saat berbicara di depan umum (public speaking). Latihan dalam kelompok selain mengurangi tingkat kecemasan, namun juga membawa manfaat lainnya, antara lain kesempatan, berlatih, memperoleh feedback dari sesama teman dan pengetahuan.

(Asiyah, 2017), menyatakan dalam kegiatan dakwahnya, seorang dai diharapkan mempunyai karakter atau ciri khas public speaking karena hal ini merupakan salah satu kompetensi yang sebaiknya dikuasai oleh dai. Seorang dai yang mengaplikasikan kekuatan retorika dan daya tarik, saat menyampaikan 
ceramah menggunakan intonasi, susunan kalimat serta pengolahan kata yang tepat merupakan karakter dari public speaking. Dengan banyaknya bekal yang dimiliki oleh dai, maka hal ini dapat mempermudah dai dalam menjalankan tugas dakwahnya. Kompetensi dai dalam berdakwah menjadi lebih kompeten dengan adanya Public speaking. (Oktavianti \& Rusdi, 2019), menyampaikan agar anak-anak terbiasa dengan Public speaking maka perlu dikenalkan sejak usia dini saat sudah mulai menginjak bangku sekolah. Di dalam pelaksanaan pengabdian kegiatan masyarakatnya, terdapat kendala dari anakanak yang belum berani untuk berbicara di depan kelas, namun dari tim penabdian membantu anak-anak sesuai dengan pemahaman yang mereka miliki. Kegiatan Pengabdian Masyarakat tentang public speaking diadakan untuk anak-anak dan remaja di Dusun Puluhan supaya mereka sadar akan pentingnya ketrampilan public speaking dan juga sebagai bekal kelas saat berinteraksi dengan masyarakat sekitar. Berbicara adalah salah satu kebutuhan, anugerah dan keterampilan bagi manusia. Sedangkan public speaking merupakan keterampilan yang lebih spesial dari sekedar berbicara dengan orang lain. Public speaking membutukan tekad dan keberanian yang kuat dan persiapan yang lebih dari sekedar berbicara. Menurut (Girsang, 2018), semua manusia sejatinya dapat berbicara namun hanya sebagian yang dapat merangkai katakata menjadi bahasa yang indah dan dapat menarik publik untuk mendengarnya. Jadi, secara sederhana public speaking artinya kemampuan berbicara dengan melakukan "permainan" bahasa di depan publik. Public speaking atau berbicara di depan umum sudah sering kita jumpai di jaman maju saat ini. Semua pribadi diharapkan lancar berbicara di depan umum untuk menyampaikan maksudnya.

Tujuan yang diinginkan dari kegiatan pengabdian kepada masyarakat "Peningkatan Public Speaking Bagi Siswa SMK Bina Nusa Slawi" adalah sebagai berikut:

1. Memberikan pengetahuan terkait Peningkatan skill Public Speaking.

2. Meningkatkan keterampilan berbicara siswa

3. Meningkatkan kualitas dan mental siswa

4. Mengatasi rasa takut untuk berbicara di hadapan orang banyak

5. Mempersiapkan diri siswa/i dalam memasuki jenjang perkuliahan dan kerja.

Berdasarkan penjabaran tersebut maka penulis memilih judul Peningkatan Publik Speaking Bagi Siswa SMK Bina Nusa Slawi. Dengan adanya kegiatan PKM ini diharapkan siswa lebih familiar dengan public speaking dan menyampaikan presentasi di depan kelas dengan kaidahkaidah yang sesuai dengan tata cara dalam public speaking.

\section{METODE}

Metode kegiatan yang disampaikan kepada para siswa di SMK Bina Nusa Slawi adalah perpaduan antara ceramah dan praktik. Metode ceramah dan praktik masih menjadi pilihan para guru di dalam kelas. Metode tersebut merupakan bentuk penyajian bahan pengajaran melalui penerangan dan penuturan lisan oleh pengajar kepada siswa tentang suatu topik materi. Dalam metode tersebut, guru menggunakan berbagai alat bantu peraga seperti gambar, benda, barang tiruan dan lain-lain.

Terdapat 3 orang pembicara yang menyampaikan arahan, yang pertama yaitu Ibu Mutiara yang bertindak selaku moderator acara dan sekaligus 
menyampaikan pengenalan awal terkait public speaking kepada para siswa. Sehingga siswa memiliki basic knowledge sebelum materi inti diberikan.

Berikutnya adalah kegiatan inti yang disampaikan oleh Bapak Syaefani pada mengenai public speaking. Pembicara selain memberikan materi inti terkait public speaking juga berbagi pengalaman terkait pelatihan public speaking yang telah diikutinya. Peserta juga diajak praktik public speaking dalam bahasa Indonesia maupun Bahasa Inggris. Selanjutnya arahan terakhir disampaikan oleh Ibu Iin Indrayanti, beliau memberikan penguatan kepada pronunciation (cara pelafalan) teks dalam bahasa Inggris. Sehingga siswa dapat membunyikan kata dalam Bahasa inggris dengan benar. Supaya mempermudah dan mengingat siswa belajar public speaking, kami bekali siswa dengan modul jadi siswa dapat mengulangi kembali di rumah. Di akhir sesi, peserta kami meminta untuk mengisi Evaluasi Kegiatan dengan mengisi formulir online yang telah disediakan oleh Tim P3M.

\section{HASIL DAN PEMBAHASAN}

Kegiatan PKM di SMK Bina Nusa Slawi dilaksanakan pada Selasa, 22 Juni 2021 yang dilaksanakan oleh 3 dosen, 2 mahasiswa dan 1 staf dari Unit Pusat Penelitian dan Pengabdian Kepada Masyarakat, serta diikuti oleh 20 orang mahasiswa. Kegiatan ini walaupun dilaksanakan secara tatap muka di masa pandemik namun pelaksanaannya tetap memperhatikan prokes. Pelaksanaan kegiatan pukul 10.00-11.30 wib. Sebagian besar siswa berasal dari jurusan Teknik Sepeda Motor (TSM).

Aktivitas awal dimulai dengan pengenalan dan Brainstorming oleh Ibu Mutiara selama kurang lebih 15 menit. Dengan gaya yang santai dan lugas serta bahasa yang mudah dipahami oleh siswa, mereka diajak untuk mengenal public speaking beserta manfaatnya. Pengenalan public speaking pun diberikan secara interaktif kepada para siswa. Hal ini dilakukan sebagai bentuk pre-activity dalam menumbuhkan rasa percaya diri dan memacu keatifian dalam menyampaikan gagasan ataupun ide di depan teman-teman lain di dalam kelas. Beberapa siswa dengan semangat menjawab pertanyaan yang berkaitan dengan pengalaman mereka selama belajar di jurusan Teknik Sepeda Motor di SMK Bina Nusa Slawi dan apa cita-cita serta impian mereka di masa depan.

Pembicara juga menyampaikan pengalamannya seputar public speaking. Sehingga hal ini dapat menjadi gambaran awal siswa untuk memahami public speaking. Aktivitas berikutnya disampaikan oleh Bapak Syaefani sekitar 60 menit. Terlebih dahulu, siswa dibagikan modul berisikan pengertian, manfaat, jenis dan teknik dalam public speaking sesuai dengan referensi yang digunakan. Modul dibagikan terlebih dulu agar siswa dapat menyimak melalui modul tersebut.

Pertama-tama pembicara memperkenalkan diri terlebih dulu dengan mengunakan teknik public speaking visual impact, dengan cara menunjukkan uang 100 ribu kepada peserta, menawarkan kepada peserta, melipat ke dalam bentuk yang lebih kecil, menawarkan lagi pada peserta, menginjak uang tersebut dan menawarkan lagi pada peserta. Dari awal penawaran hingga akhir peserta selalu menjawab mau untuk menerima. Pembicara menyampaikan pada peserta bahwa dari gambaran tersebut sama halnya dengan diri manusia, tak peduli apakah kaya atau miskin, sukses atau masih berjuang, hal ini tidak akan pernah mengurangi nilai kita sebagai manusia yang penuh potensi. Salah satu potensi yang dibedah sesuai kegiatan PKM ini yaitu soft skill public speaking.

Pembicara memulai menjelaskan materi inti sesuai isi modul yang dibagikan. Pertanyaan awal diberikan kepada peserta diantaranya; kenapa manusia butuh berkomunikasi?, Apa itu public speaking?, Apakah public speaking sangat dibutuhkan 
dalam dunia kerja? Dan apa saja hambatan dalam berbicara/ komunikasi?. Pertanyaan tersebut disampaikan kepada peserta untuk mengetahui pemahaman peserta seputar public speaking, selain hal tersebut juga disampaikan beberapa hal oleh pembicara diantaranya; manfaat dan tujuan public speaking, masalah dalam public speaking, gejala-gejala tertekan/ nerveous, penyebab kecemasan, cara mengatasi kecemasan, cara meraih percaya diri, Teknik Showmanship (teknik mengatur gesture atau penampilan saat kita tampil), teknik membuka, menyampaikan dan menutup presentasi, presentasi singkat dalam bahasa Inggris. Peserta ditunjuk oleh pembicara untuk mempraktikkan presentasi dalam bahasa Inggris di depan kelas. Sesi terakhir diisi oleh Ibu Iin Indrayanti yang menyampaikan review materi public speaking dan sharing kepada siswa tentang Pronunciation (pelafalan bunyi dalam bahasa inggris). Pembicara kembali mengulangi teks yang telah disampaikan oleh pembicara sebelumnya. Berikut dokumentasi pelaksanaan PKM;

Gambar 1:

Pembukaan/ Perkenalan oleh Ibu Mutiara terkait kegiatan PKM

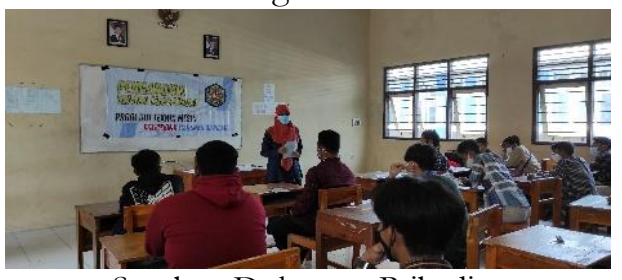

Sumber: Dokumen Pribadi

Gambar 2:

Penjelasan awal terkait teori Public Speaking

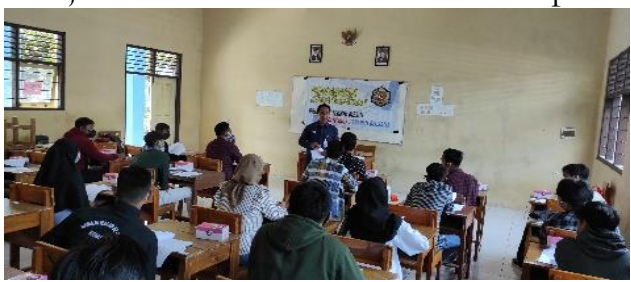

Sumber: Dokumen Pribadi
Gambar 3:

Praktik Public Speaking siswa berpasangan

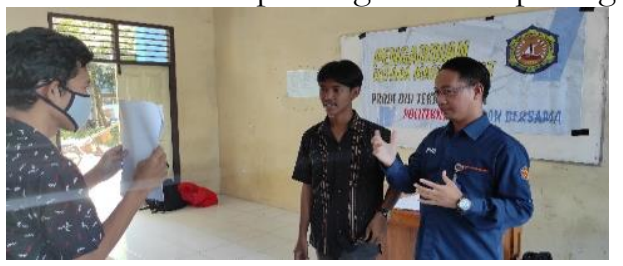

Sumber: Dokumen Pribadi

Gambar 4:

Foto Bersama siswa dan Tim PKM

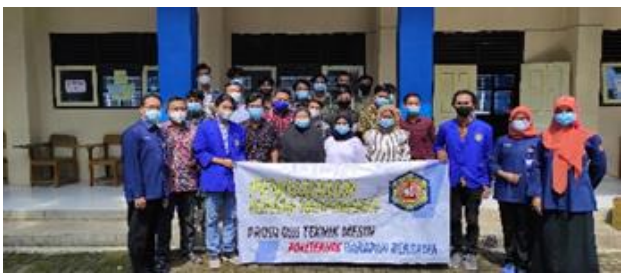

Sumber: Dokumen Pribadi

\section{KESIMPULAN}

Pengabdian kepada masyarakat di SMK Bina Nusa Slawi terlaksana dengan baik dan antusiasme para siswa luar biasa. Siswa dapat terbantu dengan adanya kegiatan PKM ini karena mereka mendapatkan pengetahuan seputar public speaking dan teknik presentasi yang benar. Siswa lebih percaya diri dan yakin untuk tampil presentasi di depan kelas.

Siswa juga kita informasikan beberapa tokoh public speaking yang terkenal untuk ditonton dan dicermati baik-baik melalui media lain seperti YouTube sehingga ada role model yang bisa mereka tiru. Selain itu, kegiatan ini dapat memberikan inspirasi kepada mitra yaitu SMK Bina Nusa Slawi untuk dapat menyusun, mengenalkan dan membawakan materi di kelas dengan metode lain yang lebih menyenangkan. Serta memotivasi para guru sekolah untuk dapat mengembangkan bahan ajar.

Dari hasil kegiatan pengabdian kepada masyarakat terdapat saran sebagai berikut yaitu: (1) Sebaiknya siswa selalu diberikan arahan terkait cara presentasi yang benar yang sesuai dengan kaidah-kaidah public speaking, sehingga siswa menjadi terbiasa; (2) Lebih ditingkatkan lagi untuk penyampaian presentasi dalam bahasa 
inggris karena bahasa inggris merupakan bahasa komunikasi internasional dan sangat dibutuhkan di dunia kerja.; (3) Guna meningkatkan kemampuan public speaking, diharapkan siswa sering memutar tanyangan youtube atau video tokoh-tokoh public speaking seperti; Mario Teguh, Ongky Hojanto, Tung Desem Waringin, Ari Ginanjar Agustian, Andrie Wongso, Ippho Santosa, James Gwee

\section{DAFTAR PUSTAKA}

Aryadillah. (2017). Kecemasan Dalam Public Speaking (Studi Kasus Pada Presentasi Makalah Mahasiswa). Cakrawala, 17(2), 198-206. https://doi.org/10.31294/jc.v17i2.25 88

Asiyah, S. (2017). Public Speaking dan Konstribusinya Terhadap Kompetensi DAI. Jurnal Ilmu Dakwah, 37(2), 198214. https//doi.org/10.21580/jid.v37. 2.2705

Fitrananda, C. A., Anisyahrini, R., Iqbal, M., Studi, P., Komunikasi, I., \& Pasundan, U. (2018). Pelatihan Public Speaking untuk Menunjang Kemampuan Presentasi Bagi Siswa SMAN 1 Margahayu Kabupaten Bandung. Jurnal Pengabdian Kepada Masyarakat MADANI, 4(2), 6669. http://dx.doi.org/10.53834/mdn. v4i2.507

Girsang, L. R. (2018). Public Speaking Sebagai bagian dari Komunikasi Efektif (Kegiatan PKM di SMA Kristoforus 2, Jakarta Barat). Jurnal Pengabdian Dan Kewirausahaan, 2(2), 8185.

http://dx.doi.org/10.30813/jpk.v2i2.1 359
Oktavianti, R., \& Rusdi, F. (2019). Belajar Public Speaking Sebagai Komunikasi Yang Efektif. Jurnal Bakti Masyarakat Indonesia, 2(1), 117-122. https://doi.org/10.24912/jbmi.v2i1.43 35

Raja, F. U. (2017). Anxiety Level in Students of Public Speaking: Causes and Remedies. Journal of Education and Educational Development, 4(1), 94. https://doi.org/10.22555/joeed.v4i1.1 001

Tridinanti, G. (2018). The Correlation between Speaking Anxiety, SelfConfidence, and Speaking Achievement of Undergraduate EFL Students of Private University in Palembang. International Journal of Education and Literacy Studies, 6(4), 35. https://doi.org/10.7575/aiac.ijels.v.6n. 4p.35 